\title{
Penerapan Ekologi Arsitektur Pada Bangunan AEON Mall dan Bintaro Jaya Xchange
}

\author{
*Muhammad Farras Baskara', Yeptadian Sari² \\ 1,2 Jurusan Arsitektur, Fakultas Teknik, Universitas Muhammadiyah Jakarta, Indonesia \\ 2015460027@ftumj.ac.id
}

*Alamat korespondensi, Masuk: 16 Nov. 2020, Direvisi: 28 Nov. 2020, Diterima: 31 Des. 2020

\begin{abstract}
ABSTRAK: Pusat perbelanjaan adalah tempat untuk beraktivitas secara bebas mulai dari bercanda, berbincang dan tempat untuk menyediakan kebutuhan sehari-hari. Pencahayaan alami berfungsi untuk mendapatkan pencahayaan dari cahaya matahari dan berguna bagi kesehatan serta penghematan energi. pusat perbelanjaan ini menerapkan sistem senyum untuk kehidupan yang berarti harus berdampak positif untuk masyarakat dan lingkungan. Pusat perbelanjaan menjadi bagian dari strategi untuk perkembangan kota dan sarana penunjang kebutuhan sehari-hari. Metode yang digunakan adalah metode deskriptif kualitatif karena penelitian ini berisikan tentang fakta, akurat dengan menggunakan narasi untuk menjelaskan gambar. Penerapan yang akan digunakan yaitu aspek tapak bangunan, aspek sirkulasi dan aksesibilitas, aspek material dan aspek fasad bangunan. Tujuan dari penelitian ini adalah menjadi acuan dalam mendesain pusat perbelanjaan dengan memberikan dampak positif ke alam. Serta menjadi inspirasi dalam pembuatan mal dengan hemat energi. Hasil dan kesimpulan dari penelitian ini adalah AEON Mall dan Bintaro Jaya Xchange sudah menerapkan beberapa aspek ekologi arsitektur dari pencahayaan alami, penggunaan material alami, penempatan sirkulasi yang tepat dan penggunaan teknologi panel surya.
\end{abstract}

Kata kunci: Ekologi, ekologi arsitektur, penerapan ekologi arsitektur, aspek penerapan ekologi arsitektur.

\begin{abstract}
Shopping center is a place to do free activities ranging from joking, talking and a place to provide daily needs. Natural lighting serves to get lighting from sunlight and is useful for health and energy saving. This shopping center applies a smile system for life, which means it must have a positive impact on the community and the environment. Shopping centers become part of the strategy for the development of the city and supporting means of daily needs. The method used is the qualitative descriptive method because this research contains facts, accurate by using narration to explain the image. The application to be used is aspects of building footprint, aspects of circulation and accessibility, material aspects, and aspects of building facades. The purpose of this research is to be a reference in designing shopping centers by giving a positive impact on nature. As well as being an inspiration in the manufacture of malls with energy-saving. The results and conclusions of this study are AEON Mall and Bintaro Jaya Xchange have implemented several aspects of architectural ecology of natural lighting, the use of natural materials, the placement of proper circulation, and the use of solar panel technology.
\end{abstract}

Keywords: Ecology, architectural ecology, application of architectural ecology, aspects of the application of architectural ecology.

\section{PENDAHULUAN}

Pembangunan yang baik adalah memikirkan segala aspek positif maupun negatif untuk lingkungan. Dalam merancang bangunan sering kali tidak memperhatikan keselarasan pada alam dan dapat menimbulkan globalisasi. Salah satu penyebab global warming yang paling besar itu diakibatkan oleh sektor energi, terutama kelistrikan terutama dalam pemborosan energi. Untuk itu, rancangan arsitektur ikut bagian dalam mengurangi globalisasi dalam pembangunan terutama bangunan pusat perbelanjaan. Karena itu pembangunan dengan menggunakan jasa sudah mengetahui gejala yang tidak mendukung pembangunan dengan alam melalui data dan analisis yang mendukung.

Dalam penelitian ini membahas tentang bangunan pusat perbelanjaan dengan menggunakan konsep ekologi arsitektur. Ada 2 objek pusat perbelanjaan dalam penelitian ini, yaitu: AEON Mall Jakarta Garden City berada di Jakarta dan Bintaro Jaya Xchange berada di Tangerang. Untuk AEON Mall Jakarta Garden City berkonsep ekologi serta menggunakan sistem panel surya. Ada 
beberapa aspek dalam konsep ekologi yang dapat diterapkan pada bangunan, yakni: aspek tapak bangunan, aspek penataan bangunan, aspek material bangunan dan aspek fasad bangunan [1].

\section{Perumusan Masalah}

Perumusan masalah dalam penelitian ini adalah apa saja yang dapat diterapkan dalam aspek ekologi arsitektur pada AEON Mall dan Bintaro Jaya Xchange?

\section{Tujuan dan manfaat penelitian}

1. Menjadi acuan dalam mendesain pusat perbelanjaan dengan memberikan dampak positif bagi lingkungan.

2. Menambah ilmu pengetahuan khusus yang berkaitan dengan arsitektur ekologi dengan pusat perbelanjaan.

3. Memberikan pengetahuan tentang penerapan aspek ekologi arsitektur.
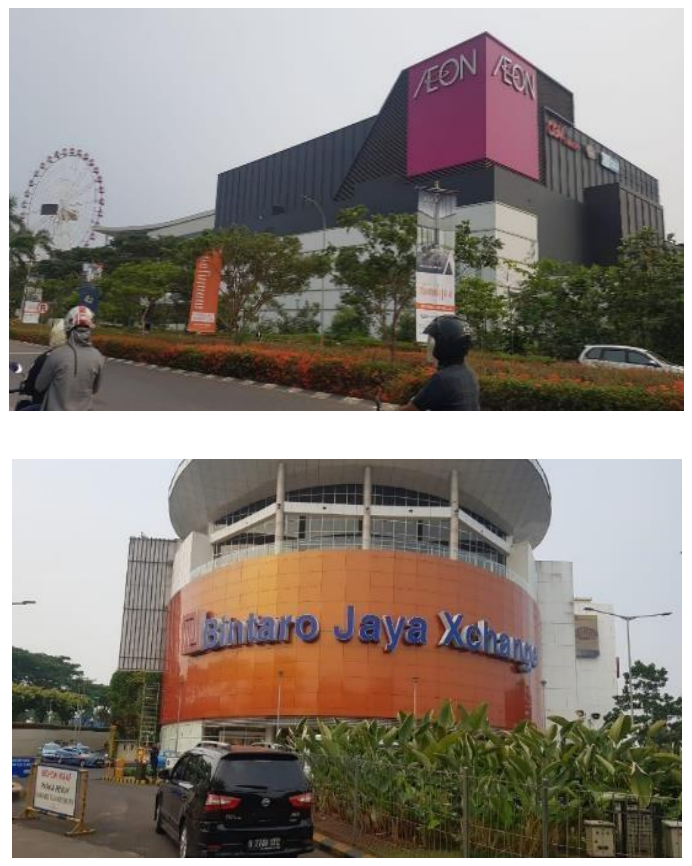

Gambar 1. AEON Mall Jakarta Garden City dan Bintaro Jaya Xchange.

Sumber: Dokumentasi Pribadi, 2019

\section{STUDI PUSTAKA}

\section{Definisi Ekologi Arsitektur}

Dalam merancang bangunan tidak dapat mengelak dari kerusakan alam [2]. Namun demikian, arsitektur ekologi dapat menjadi solusi permasalahan tersebut. Karena desain dirancang dengan memperhatikan beberapa aspek, meliputi: aspek iklim, aspek lingkungan ekosistem, dan aspek bahan material bangunan yang dipakai.

Arsitektur ekologi dapat diartikan sebagai tempat yang dipenuhi dengan kebutuhan [3]. Kebutuhan terhadap kegiatan fisik maupun psikologis manusia yang mempertimbangkan timbal balik terhadap kelestarian alam. Pendekatan konsep ekologi arsitektur yang merupakan konsep bangunan dengan menyadarkan dan memperhatikan pentingnya keberlangsungan ekosistem. Dalam pembangunan mengurangkan efek negatif terhadap bangunan dan lingkungan [4].

Konsep ekologi arsitektur merupakan yang memanfaatkan potensi penataan lingkungan konsep penataan dan dalam menggunakan teknologi didasari ramah [5]. Pola perencanaan dan perancangan Arsitektur Ekologi adalah sebagai berikut :

1. Elemen-elemen arsitektur mampu melindungi bangunan dari sinar panas, angin dan hujan.

2. Penggunaan energi terdapat dalam material yang digunakan dengan efektif, dengan caracara:

a. Memperhatikan cuaca dan iklim setempat.

b. Substitusi, meminimalkan dan mengoptimalkan sumber energi yang tidak dapat diperbaharui.

c. Penggunaan bahan material bangunan yang dapat menghemat energi.
d. Penggunaan teknologi dengan memperhatikan lingkungan sekitar.

\section{Definisi Aspek Ekologi Arsitektur}

Menurut KBBI arti aspek secara umum adalah sudut pandang, yang berarti mempertimbangkan segala sesuatu tindakan dari berbagai aspek. Aspek penerapan arsitektur ekologi dapat merujuk pada teori arsitektur dan selalu dikaitkan dengan aspek estetika, struktur dan fungsi [1]. Aspek Ekologi Arsitektur akan menentukan dalam membangun bangunan yang harus mempertimbangkan sisi positif. Supaya tidak menimbulkan kerusakan terhadap lingkungan sekitar dan ekosistem.

\section{Aspek Tapak Bangunan}

Aspek pola penataan ruang dan massa bangunan merupakan aspek yang membahas tentang ruang luar pada tapak [1], yaitu:

1. Zonasi

Dengan membedakan zonasi privat, zonasi semi privat, zonasi publik, zonasi semi publik, dan zonasi servis. 
2. Orientasi bangunan

Membahas tentang peletakan massa bangunan dengan arah matahari. Orientasi bangunan juga berdampak pada pencahayaan dan radiasi matahari yang masuk.

3. Aksesibilitas dan sirkulasi

Dengan menandai dan membedakan sirkulasi main entrance, second entrance dan servis.

4. Keselarasan Dengan Lingkungan

Desain bangunan dengan berkarakter ekologi arsitektur berserta vegetasi memberikan keseimbangan dengan lingkungan. Melalui pengoptimalan view serta pengalaman visual yang berarti penghuni dapat merasakan kegiatan menyatu dengan alam.

\section{Aspek Penataan Bangunan}

Pada prinsip tatanan ruang terbagus menjadi dua, yaitu [6]:

1. Single loaded adalah sirkulasi dengan 1 jalur akses yang di mana pada bagian sisi lain langsung menghadap jendela atau ruang luar

2. Double loaded adalah sirkulasi dengan 1 jalur akses tetapi diapit oleh kedua sisi.

\section{Aspek Material Bangunan}

Pemilihan material akan berperan penting untuk kenyamanan terhadap penghuni. Jika pemilihan material yang tepat akan menciptakan bangunan yang berkualitas dan ramah lingkungan. Berdasarkan tingkat teknologi dan pengaruhnya terhadap ekologi dan kesehatan, bahan bangunan dapat digolongkan sebagai berikut [1]:

1. Bahan bangunan yang dapat dibudidayakan kembali

2. Bahan bangunan alam yang dapat digunakan kembali

3. Bahan bangunan buatan yang dapat didaur ulang

4. Bahan bangunan alam mengalami transformasi sederhana

5. Bahan bangunan yang mengalami beberapa tingkat perubahan transformasi

6. Bahan bangunan komposit

\section{Aspek pada Fasad Bangunan}

Menurut Chrisnesa dan Shellyn (2017) Mengenai pembentukan massa bangunan memperhatikan segala sesuatu pada iklim dan lingkungan sekitar. Dari aspek orientasi bangunan dari radiasi matahari, melindungi ruang utama dapat menimbulkan panas serta bukaan untuk penyegaran udara [2].

1. Perlindungan terhadap radiasi matahari
2. Perlindungan terhadap radiasi pada fasad dapat menambahkan kanopi atau penghalang lainnya. Selain itu, juga dapat diterapkan dengan menggunakan sistem kaca pintar dan penghalang sinar matahari (sun shading).

3. Pencahayaan

Pencahayaan pada bangunan dengan memaksimalkan cahaya matahari. Dengan begitu, harus memperhatikan terbit dan terbenamnya matahari.

\section{METODE PENELITIAN}

Penelitian kualitatif dapat digunakan untuk meneliti objek pada kondisi alamiah. Peran peneliti sebagai pelengkap kunci, teknik pengumpulan data menerapkan triangulasi, analisis data bersifat induktif dan hasil penelitian lebih menekankan makna daripada penalaran untuk membentuk kesimpulan [7]. Penelitian deskriptif kualitatif untuk mendeskripsikan gambar dan fenomena, baik bersifat alamiah maupun fiksi, lebih mengamati mengenai karakteristik, kualitas, keterkaitan antar aktivitas.

\section{Tahapan Penelitian}

Dalam melakukan penyusunan penelitian yang baik, maka harus dilakukan dengan beberapa tahapan. Tahapan tersebut sesuai dengan pemikiran yang sudah disusun secara sistematis.

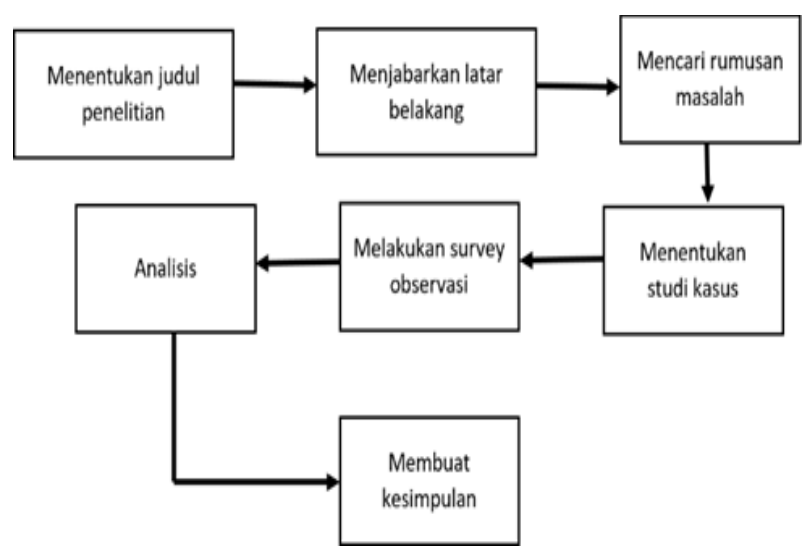

Gambar 2. Tahapan Penelitian

Sumber: Dokumentasi Pribadi, 2019

Berikut adalah penjabaran tahapan penelitian yang dilakukan dalam melakukan penelitian ini, sebagai berikut:

1. Menentukan rumusan masalah

Menentukan rumusan dilakukan untung menentukan inti dari penelitian ini. Masalah yang mau dibahas yang nantinya akan dilengkapi oleh data dan analisis. 
2. Melakukan survei literatur

Sebelum menentukan studi kasus, yang akan dilakukan adalah melakukan studi literatur. Melakukan studi literatur untuk mencari informasi bangunan pusat perbelanjaan apa saja yang cocok untuk konsep ekologi.

3. Menentukan studi kasus

Dalam menentukan studi kasus harus dibarengi dengan survei lapangan. Ada beberapa pusat perbelanjaan yang di survei, dari yang memenuhi kriteria ekologi arsitektur dan tidak memenuhi. Ditahap ini harus di dasar prinsip arsitektur ekologi agar terjadi kecocokan dengan studi kasus.

4. Melakukan survei literatur

Sebelum menentukan studi kasus, yang akan dilakukan adalah melakukan studi literatur. Melakukan studi literatur untuk mencari informasi bangunan pusat perbelanjaan apa saja yang cocok untuk konsep ekologi.

5. Pencarian data dan analisis

Tahap selanjutnya adalah pencarian data, pencarian data harus disesuaikan dengan rumusan masalah penelitian. Karena data tersebut akan dianalisis. Setelah mendapatkan data, tahap selanjutnya adalah melakukan analisis. Yang dilakukan dalam tahap ini, memecahkan masalah kompleks dalam data sehingga bisa mudah dipahami.

6. Menentukan judul penelitian

Judul dari penelitian ini adalah kajian ekologi terhadap bangunan pusat perbelanjaan. Dalam kajian ini, mengetahui apa saja elemen-elemen ekologi yang terdapat pada pusat perbelanjaan. Elemen tersebut yang bisa menjaga lingkungan serta bisa menghemat energi. Selain itu cara kerja konsep ekologi adalah membuat pengguna atau penghuni di pusat perbelanjaan nyaman. Kenyamanan dibuat dengan adanya bukaan pencahayaan alami di dalam bangunan serta penghalang radiasi matahari.

7. Menjabarkan latar belakang

Latar belakang berisikan alasan alam pengambilan judul penelitian yang diulas berdasarkan permasalahan yang ada. Permasalahan tersebut dalam membangun bangunan tidak banyak yang mempertimbangkan lingkungan. Tidak memikirkan apa dampak negatif serta positifnya jika dibangun bangunan di lingkungan tersebut. Dengan adanya penelitian ini, jadi dapat memahami elemen apa saja yang dapat mendukung lingkungan. Serta elemen apa saja yang dapat membuat penghuni merasakan kenyamanan dan kesehatan.

8. Membuat kesimpulan

Langkah terakhir adalah membuat kesimpulan. Kesimpulan dibuat setelah semua data dan analisis dilakukan dengan lengkap. Kesimpulan penelitian ini akan mengacu ke tujuan penelitian serta manfaat penelitian.

\section{HASIL DAN PEMBAHASAN}

\section{Aspek Tapak}

\section{Orientasi Bangunan}

Secara orientasi bangunan yang menghadap ke arah timur sangat baik, dikarenakan untuk pencahayaan sinar matahari. Sinar matahari di pagi hari baik untuk kesehatan dan pada siang hari pencahayaan matahari tidak menyilaukan karena matahari berada di atas bangunan. Tetapi pada siang hari, sinar matahari panas dan mengandung radiasi, untuk itu matahari pada siang hari tidak baik untuk kesehatan.

Orientasi bangunan terdiri dari arah utara, timur, selatan dan barat. Pada bagian barat, tempat terbenamnya matahari dan itu akan sangat menyilaukan mengandung radiasi. Karena itu pada sisi tersebut, ditanam pepohonan yang tinggi sebagai penghalang radiasi dan menghambat silaunya sinar matahari. Pada bagian timur, tempat matahari terbenam di pagi hari. Di sisi tersebut bagus untuk kesehatan. Tetapi jika terlalu banyak sinar matahari yang masuk akan menimbulkan panas pada bangunan. Pada bagian utara arah angin yang sangat tinggi serta minimnya sinar matahari dapat menyebabkan melembapkan bangunan. Pada bagian tersebut, upaya pemilihan bahan material harus disesuaikan dan perhatikan secara mendetail.

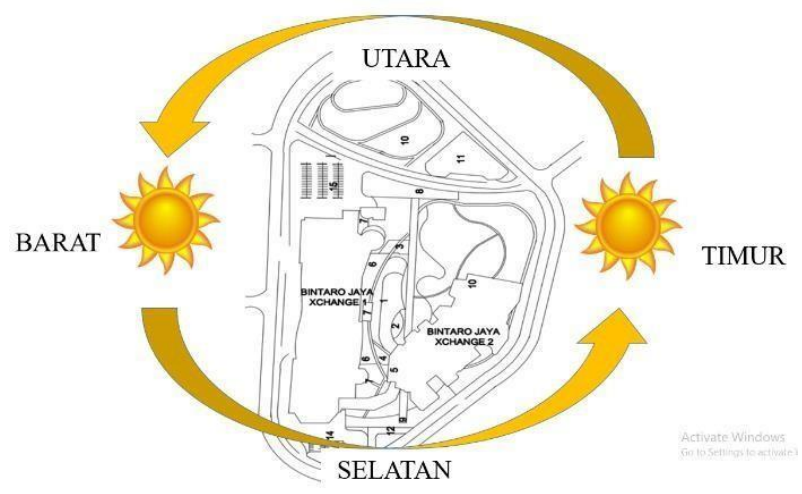

Gambar 3. Orientasi Bangunan Bintaro Jaya

Xchange

Sumber: Pribadi, 2019 


\section{Sirkulasi dan Aksesbilitas}

Sirkulasi Bintaro Jaya Xchange sedikit susah diakses. Akses menuju mal harus melewati flyover dan terowongan. Jika baru pertama kali berkunjung ke Bintaro Jaya Xchange akan kesulitan untuk menuju jalur yang benar. Ketika sudah ketemu jalur menuju mal, untuk pengendara motor harus mengitari kawasan, jika ingin memarkirkan kendaraannya. Sedangkan untuk penghuni di perumahan mengarah menteng, akses menuju mal sangat mudah hanya dengan melewati jembatan dan sampai ke tujuan.

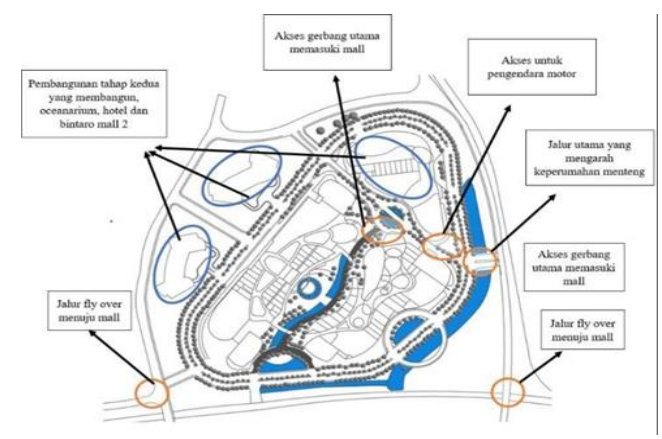

Gambar 4. Akses dan sirkulasi dalam tapak Sumber: Analisa pribadi, 2019

Penataan sirkulasi sekitar mal, banyaknya pepohonan yang mengelilingi kawasan. Dengan begitu kondisi pada sirkulasi mal tidak terlalu panas dengan banyaknya pepohonan. Pepohonan juga tinggi dan berjenis beringin, dapat saling menutupi jalan. Sirkulasi menuju mal adalah sirkulasi utama dan berukuran lebar 15 meter. Sirkulasi utama mudah diakses dari mana saja dan mengelilingi bangunan mal. Sirkulasi akses kedua menuju mal digunakan untuk pengendara motor, yang hanya berukuran 5 meter.

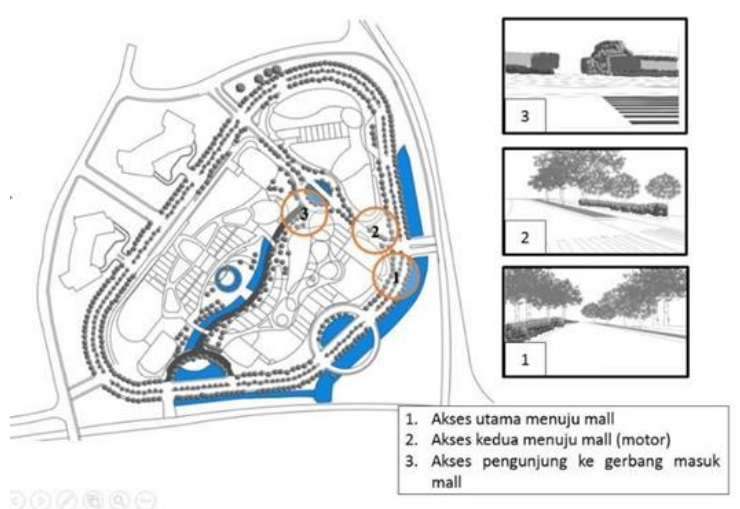

Gambar 5. Sirkulasi dan Aksesibilitas Bintaro Jaya Xchange Sumber: Pribadi, 2019

\section{Sirkulasi Bangunan}

Sirkulasi pencapaian menuju ke AEON Mall menggunakan kendaraan dengan lebar jalanan 20 meter. Sepanjang jalan banyaknya pepohonan menjadikan sejuk saat perjalanan. AEON Mall juga menyediakan halte bus untuk mudah dalam pencapaian menggunakan kendaraan umum.

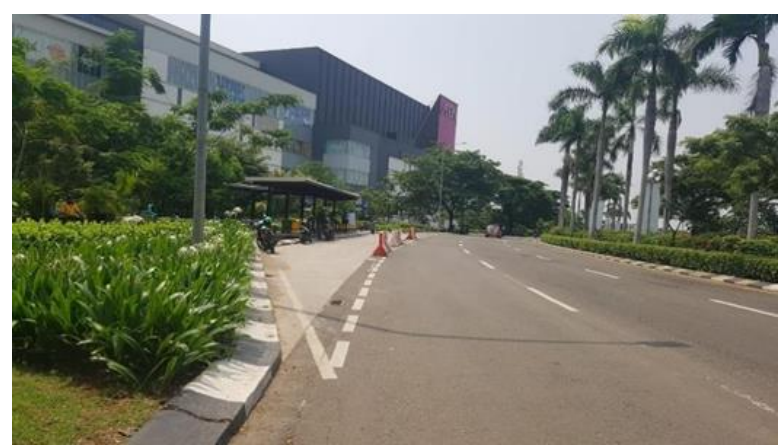

Gambar 6. Sirkulasi Utama di AEON Mall Sumber: Pribadi, 2019

Sirkulasi pencapaian untuk kendaraan motor harus melewati bundaran terlebih dahulu. Setelah itu belok ke kiri sampai ke jalur pencapaian motor. Sirkulasi tersebut berukuran 10 meter untuk 2 jalur.
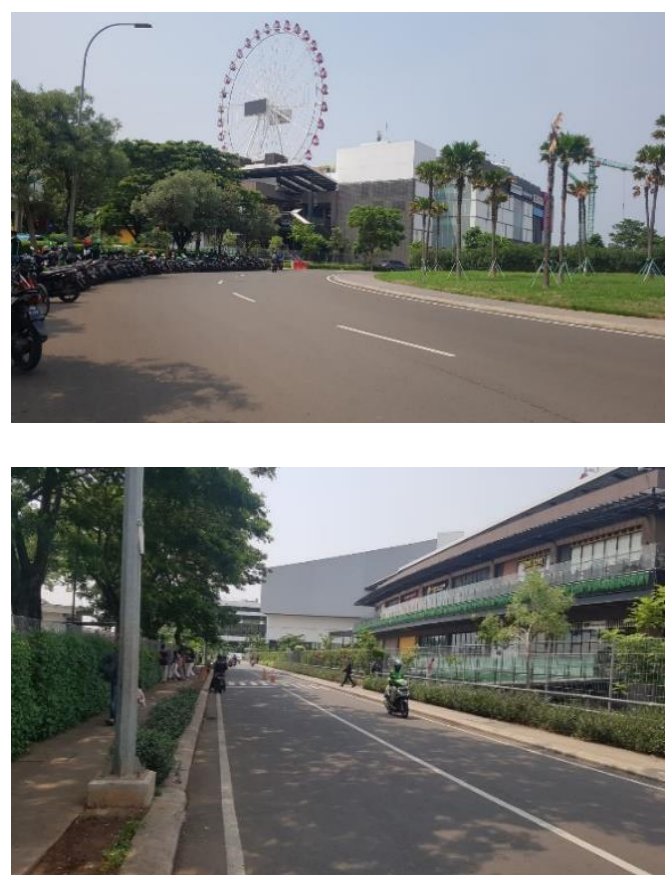

Gambar 7. Sirkulasi pencapaian jalur motor di AEON Mall Sumber: Pribadi, 2019

Sirkulasi servis AEON Mal terpisah dari sirkulasi lainnya, karena sirkulasi servis bersifat 
privat. Sirkulasi servis melewati jalur utama terlebih dahulu baru bisa sampai. Jalur servis terhubung dengan jalur kendaraan bermotor hanya beda masuk menuju jalur tersebut. Jalur sirkulasi berukuran 20 meter untuk 2 jalur.
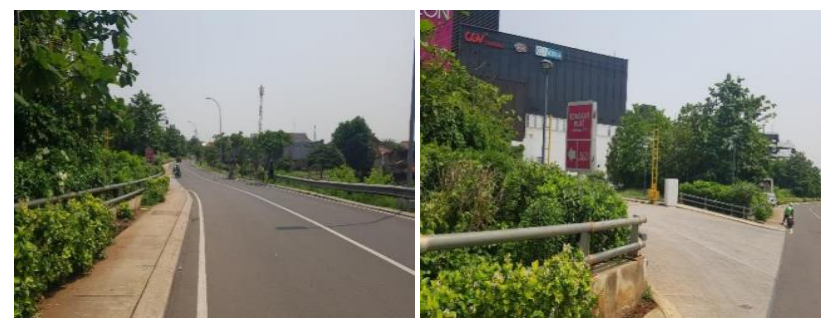

Gambar 8. Sirkulasi Servis di AEON Mall Sumber: Pribadi, 2019

Sirkulasi kendaraan khususnya yang memakai mobil pribadi dapat dilihat seperti gambar 6 . Sirkulasi tersebut mengarah ke lobi utama dan disediakan drop off yang cukup luas, jadi menghindari keramaian kendaraan saat menurunkan penumpang. Sirkulasi tersebut juga dijadikan main entrance dan terdapat sebuah papan informasi bertuliskan available parking space. Jadi pengunjung yang ingin memarkirkan kendaraannya tidak pusing memilih parkir.

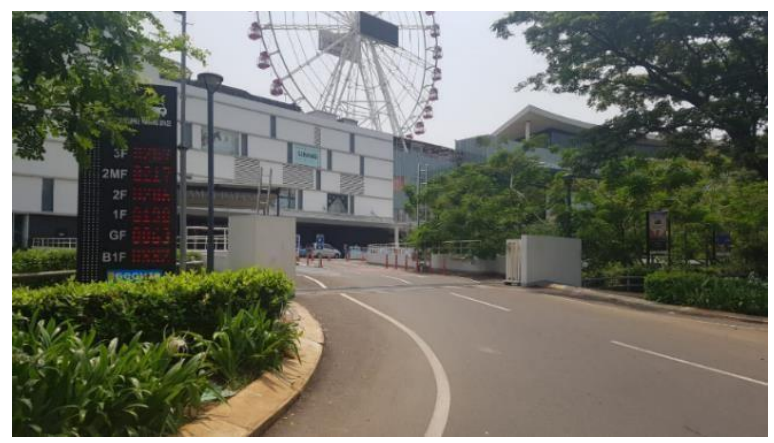

Gambar 9. Main Entrance di AEON Mall Sumber: Pribadi, 2019

\section{Aspek Material bangunan}

Material pada penutup atap Bintaro Jaya Xchange menggunakan bahan spandek Lysaght yang dibuat oleh NS BlueScope Lysaght Indonesia. Spandek yang dibuat oleh NS BlueScope Lysaght Indonesia diberi nama LYSAGHT FLEX-LOK. Adanya sistem penggabungan material atap antara Lysaght flex-lok dan baja colorbond memberikan reflektivitas matahari yang lebih baik dan massa termal yang lebih rendah. Lysaght flex-lok cocok untuk desain atap yang rumit, atap ini membutuhkan panel melengkung dan meruncing.

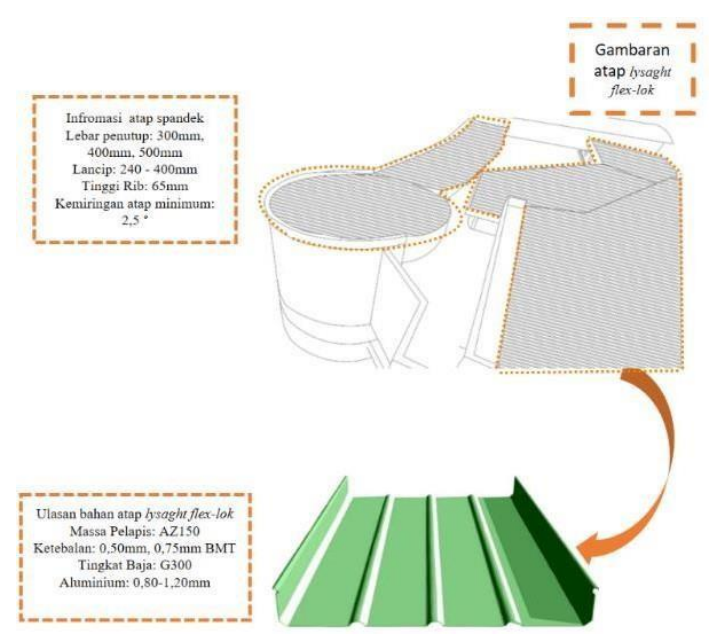

Gambar 10. Pembahasan material atap di Bintaro Jaya Xchange

Sumber: Pribadi, 2019

Pada fasad mal menerapkan material lokal dan vegetasi. Material lokal nya itu sendiri seperti kayu. Material kayu tersebut menggunakan kayu jati yang tahan lama terhadap cuaca dan tahan dari gigitan rayap. Perawatan vegetasi memerlukan bahan khusus dan memerlukan biaya yang besar. Sistem penyiramannya seperti disemprot dari atas dan penyiramannya harus sesuai prosedur, tidak kelebihan atau kekurangan. Material kayu tersebut berfungsi sebagai penghalang radiasi matahari dan dapat mengontrol penghawaan yang ada di dalam bangunan.

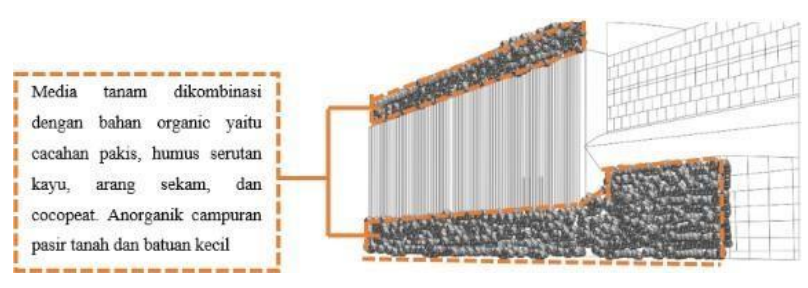

Gambar 11. Pembahasan Vegetasi di Bintaro Jaya Xchange

Sumber: Pribadi, 2019

Material pada fasad lain lebih dominan memakai keramik. Terlihat pada eksterior bangunan menggunakan keramik homogeneous tile. Material homogeneous tile pada eksterior berukuran 60x60, material itu sendiri tidak mudah tergores. Jika tergores tinggal memoles tanpa merusak motif atau bentuk dari material tersebut. Homogeneous tile nama lain dari ubin granit dan juga sebagai tiruan granit alam. Homogeneous tile untuk menurunkan suhu pada bangunan, agar mendapatkan hawa yang sejuk. 


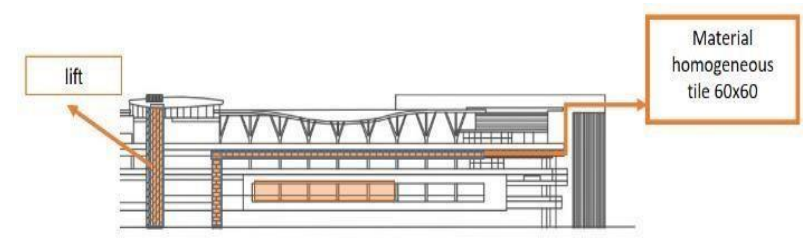

Gambar 12. Pembahasan Material Keramik di Bintaro Jaya Xchange

Sumber: Pribadi, 2019

Material yang digunakan pada area bermain menggunakan float glass bening tetapi warna di luar hijau gelap. Ketebalannya bisa mencapai $10 \mathrm{~mm}$, karena lebih terjaga dari radiasi matahari. Float glass dapat mengatur intensitas cahaya matahari ke dalam bangunan, pada fasad tersebut dipasang agar tidak terlalu silau. Dikarenakan terdapat area bermain anak di dalamnya.

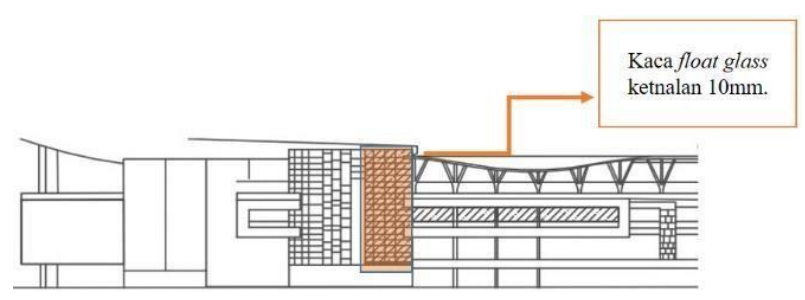

Gambar 13. Penggunaan kaca float glass di Bintaro Jaya Xchange

Sumber: Pribadi, 2019

Material pada teras menggunakan plint kayu jati. Kelebihan kayu ini adalah lebih ringan harga terjangkau, serat kayunya bisa diukir dengan indah dan terasa halus. Kayu jadi dapat menyerap panas yang dihasilkan dari sinar matahari. Itulah mengapa Bintaro Jaya Xchange menjadikan material pada teras, yang mendukung mal tersebut dikenal sebagai pusat perbelanjaan ramah lingkungan.

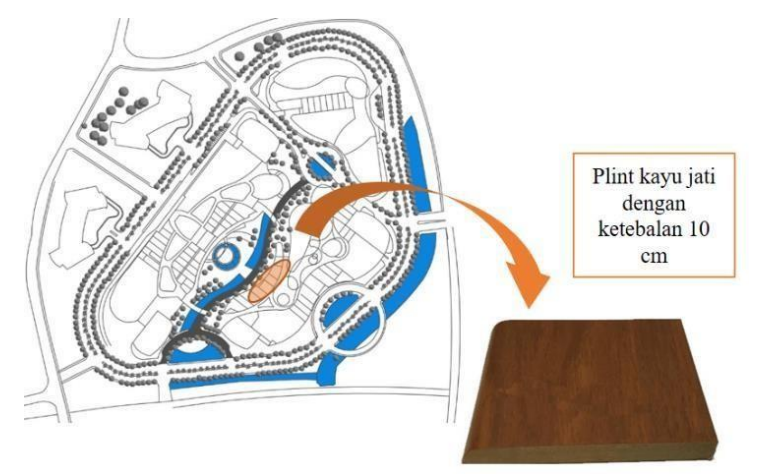

Gambar 14. Penggunaan material pada teras di Bintaro Jaya Xchange

Sumber: Pribadi, 2019

\section{Aspek Fasad Bangunan}

\section{Penghalang Sinar Matahari}

Dalam konsep ekologi arsitektur mengaplikasikan vegetasi pada fasad salah satu penanganan radiasi matahari, jadi udara di dalam bangunan tidak panas secara berlebih. Dengan begitu penghuni dapat merasakan kesejukan. AEON Mall menerapkan pengaplikasian vegetasi pada bangunan, ada beberapa fasad yang memakai vegetasi. Fasad yang menggunakan vegetasi bangunan adalah fasad depan yang diterapkan pada ruangan yang mengundang banyak pengunjung (food court, restaurant, area bermain, dan lain-lain), fasad samping yang diterapkan sebagai food court dan kafe yang berada di outdoor, fasad belakang yang digunakan untuk gedung parkir.
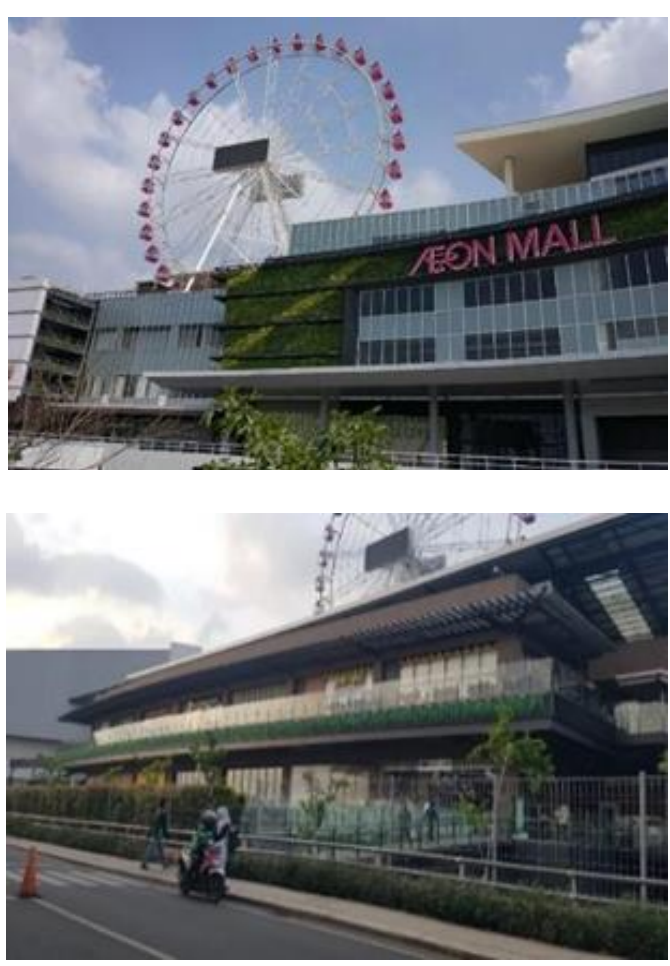

Gambar 15. Vegetasi pada fasad di AEON Mall Jakarta Garden City

Sumber: Pribadi, 2019

Kanopi yang cukup besar sebagai peneduh dari sinar matahari atau hujan, kanopi tersebut berada pada pintu masuk AEON Mall. AEON Mall juga menggunakan sun shading pada fasad samping. Sun shading untuk mengalang radiasi matahari yang masuk secara berlebih tetapi membiarkan masuk cahaya matahari. Dikarenakan dalam upaya pencahayaan alami untuk menghemat energi di bagian tersebut. 

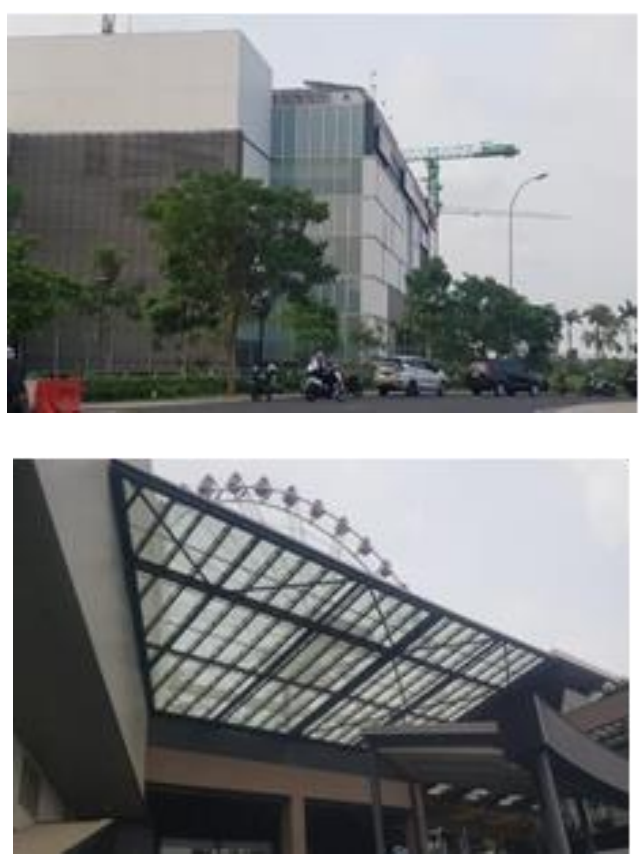

Gambar 16. Kanopi dan sun shading di AEON Mall Jakarta Garden City

Sumber: Pribadi, 2019

\section{Arah Pencahayaan Pada Bangunan}

Dalam mengarahkan bangunan ke arah pencahayaan matahari, AEON Mall memosisikan arah cahaya matahari kebagian samping bangunan. Dikarenakan site yang tidak cocok ketika diarahkan bagian depan ruangan yang membutuhkan pencahayaan. Dengan begitu fasad bagian depan diperbanyak bukaan agar banyak cahaya yang masuk. pada ruangan yang diarahkan dengan terbit terbenamnya matahari, digunakan sebagai ruko atau retail. Bahkan pada bagian barat, sirkulasi digunakan sebagai sirkulasi servis. Sedangkan pada fasad depan menempatkan pada ruangan yang sangat membutuhkan pencahayaan, yang lebih ke arah timur dan barat. Ruangan yang membutuhkan pencahayaan seperti foodcourt, dan restaurant.

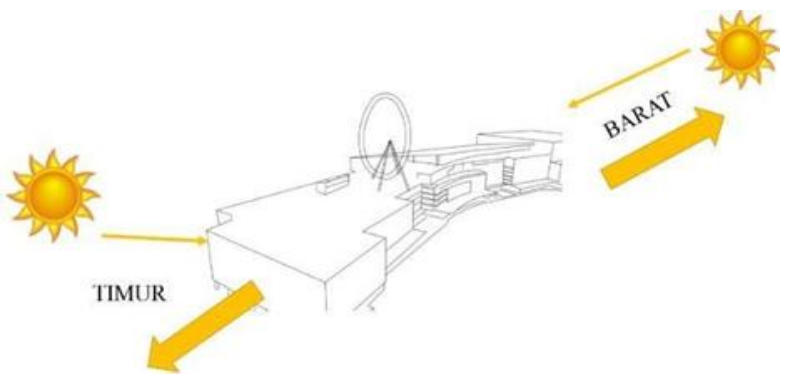

Gambar 17. Arah pencahayaan matahari di AEON Mall Jakarta Garden City

Sumber: Pribadi, 2019

\section{KESIMPULAN}

Dalam menerapkan konsep ekologi pada bangunan mal beberapa cara untuk beberapa aspek ke dalam bangunan. Dengan beberapa penerapan di pembahasan dapat menjadikan bangunan hemat energi serta berdampak positif pada bangunan. Penerapan yang dilakukan adalah orientasi bangunan, bahan material yang digunakan dan bukaan pencahayaan alami. Selanjutnya pada penelitian ini aspek-aspek yang dapat menjadi acuan konsep ekologi arsitektur. Aspek tersebut terdiri dari aspek tapak bangunan, sirkulasi dan aksesibilitas, aspek material bangunan dan aspek fasad bangunan.

\section{Aspek Tapak Bangunan}

Kesimpulan pembahasan aspek tapak bangunan, pada sisi timur dan barat sudah diterapkan bukaan pencahayaan alami pada fasad. Oleh sebab itu, cahaya matahari dapat masuk secara optimal, untuk penanganan radiasi matahari sudah ditambahkan bahan material alami yang dapat menghambat radiasi matahari.

\section{Aspek Sirkulasi dan Aksesibilitas}

Kesimpulan pembahasan sirkulasi dan aksesibilitas sudah menerapkan zonasi dan orientasi yang tepat sesuai dengan aspek ekologi arsitektur. Selain itu penataan pepohonan sekitar sirkulasi juga sudah diterapkan sehingga pengunjung dapat melewati tidak perlu takut kepanasan. Hanya pada sirkulasi parkir motor kebangunan tidak ada peneduh untuk panas dan hujan ketika ke mal. Hanya dalam parkiran sudah diterapkan peneduh untuk motor jadi ketika hujan bisa berteduh di area parkir.

\section{Aspek Material}

Kesimpulan pembahasan aspek material sudah menerapkan material bangunan alami dan ditambah dengan penanaman vegetasi pada fasad. Penambahan vegetasi akan berdampak pada penghawaan di dalam bangunan. Selain itu material atap juga menggunakan spandek Lysaght untuk mengurangi dampak radiasi matahari serta mudah dibentuk walaupun untuk desain yang rumit

\section{Aspek Fasad Bangunan}

Kesimpulan pembahasan aspek fasad bangunan menggunakan rubin granit dan kaca float yang dapat mendukung penghawaan di dalam bangunan serta menghambat pantulan cahaya matahari sehingga tidak silau ketika d dalam bangunan.

Aspek fasad bangunan terdiri dari pencahayaan dan penghalang radiasi matahari. Kedua elemen ini 
memiliki fungsi yang berguna untuk penerangan dan penghawaan di dalam bangunan. Pencahayaan ditempatkan pada ruangan yang dibutuhkan masuknya cahaya matahari sedangkan penghalang sinar matahari ditempatkan pada ruangan untuk sedikit masuknya sinar matahari.

\section{DAFTAR PUSTAKA}

[1] Suhada IA (2018) PENERAPAN PRINSIP EKO-ARSITEKTUR STUDI KASUS PERENCANAAN KAWASAN KAMPUNG WISATA PONGGOK CIBLON: Universitas Islam Indonesia141141141.

[2] Chrisnesa JS (2017) Gedung Resepsi Pernikahan Paripurna Dengan Pendekatan Arsitektur Ekologis di Yogyakarta. Yogyakarta: Universitas Atma Jaya Yogyakarta142142142.

[3] Utami AD, Yuliani S, and Mustaqimah U (2017) Penerapan Arsitektur Ekologis Pada Strategi Perancangan Sekolah Menengah Kejuruan Pertanian Di Sleman. ARSITEKTURA Vol. 15, No. 2: Hal. 340-348.

[4] Metallinou V (2006) Ecological propriety and architecture. WIT Transactions on the Built Environment Vol. 86: Hal. 15-22.

[5] Titisari EY, Triwinarto J, and Suryasari N (2012) Konsep ekologis pada arsitektur di Desa Bendosari. RUAS (Review of Urbanism and Architectural Studies) Vol. 10, No. 2: Hal. 20-31.

[6] Pynkyawati T, Alpi M, Herdarsyah R, and Amhar F (2012) Kajian Desain Sirkulasi Ruang Luar Dan Ruang Dalam Bagi Penyandang Cacat Pada Kawasan Bangunan Ciwalk (Cihampelas Walk). JURNAL ARSITEKTUR Vol. 3, No. 1.

[7] Sukmadinata NS. (2005) Metode penelitian pendidikan. Program Pascasarjana Universitas Pendidikan Indonesia dengan PT Remaja Rosdakarya. 